\title{
COLOUR TOLERANCE
}

$\mathrm{O}^{\mathrm{N}}$ February 12, the Physical Society Colour Group held its inaugural meeting at the Regent Street Polytechnic, London. In accepting the responsibility for the formation of this group, the Physical Society hopes to provide a valuable opportunity for people interested in colour, whether as physicists, chemists, dyers, industrialists or otherwise, to meet for their mutual benefit. A number of societies have already agreed to co-operate by becoming founder societies of the group and, in addition to the Physical Society, these include the British Kinematograph Society, the Illuminating Engineering Society, the Institute of Physics, the Royal Photographic Society, the Society of Glass Technology, the Society of Dyers and Colourists, and the Oil and Colour Chemists' Association.

The opening meeting was in part occupied by a discussion of the constitution of the Group, but when this had been formally adopted, a discussion on "Colour Tolerance" was held. Such a subject presents a very wide field, and was chosen intentionally for the opening meeting so as to interest as many people as possible and to provide an opportunity for each type of worker to become acquainted with the others.

In a brief introduction, it was shown that the problems of colour tolerance can be divided roughly into three, namely, the commercial aspect, in which the requirements of the customer have to be considered, the technical aspect, in which the limitations of manufacturing processes have to be taken into account, and the physical aspect, in which the specification and measurement of colour tolerances must be discussed.

Mr. R. F. Wilson, of the British Colour Council, in dealing with the commercial side of the problem, showed how valuable it is to limit the number of colours employed in any particular industry to the minimum that will satisfy the general public. In this way manufacturing costs can be very materially reduced and the irritating task of trying to differentiate between colours that in fact possess only minute differences, can be avoided. Remarkable figures for the number of colours that were used until recently in various cases, as, for example, in stockings and in the dyeing of the soles of ladies' shoes, were quoted during the discussion. Mr. Wilson also referred to the importance of the lighting on the accuracy to which colours can be matched, and appealed for more uniform lighting conditions. $\mathrm{He}$ instanced the case of a firm that has an excellently equipped viewing room and yet often encounters difficulties because the very perfection of its lighting arrangements is so different from that employed by the retailer. The question of a standard daylight lamp was raised by several speakers, while it was also pointed out that for many purposes, of which theatre lighting and interior decoration may be cited, artificial lighting is more important, so that a standard artificial lamp is also very desirable.

A point raised by $\mathrm{Mr}$. Wilson and echoed by other speakers was the often serious trouble that arises when persons with defective colour vision are employed in colour industries. Colour-blindness may be regarded as a somewhat extreme case; but it is evident that even slightly abnormal vision may affect the ability of an observer to detect small colour differences correctly.

Mr. H. W. Ellis, of the Clayton Aniline Co., dealt with the technical limitations of dyeing processes and in his paper he demonstrated how the limits to which the dyer should be asked to work ought to be determined very closely by the purpose to which a dyed material is to be put. A material may sometimes have to be made fast to light, sometimes to washing, sometimes to the effects of perspiration and so on, but only in exceptional cases would the expense of using a dye fast under all conditions be justified. Thus while curtain material should be fast to light, this is of little importance in the case of ladies' underwear, which must, however, be made fast to washing.

Again, it may happen that the colour of a surface varies according to the direction in which it is viewed, and when several different viewing angles are presented simultaneously, as for example with hats, it becomes important that the change in colour with angle should be held within close limits. Samples were also shown to demonstrate the change in colour that results with given changes in the chemical conditions of dyeing; but perhaps the most striking feature of Mr. Ellis's paper was the evidence it afforded that tolerance questions may arise in many and varied forms.

Mr. J. W. Perry, of Messrs. Adam Hilger, Ltd., had the task of discussing the physical aspect of colour tolerances. He indicated how tolerances can be expressed in the standard C.I.E. chart or, if desired, on an oblique projection of the chart known as the rectangular uniform chromaticity scale (R.U.C.S.), and then developed equations from which the tolerance, defined initially in terms of the additive primaries of the C.I.E. system, can be transformed into the terms of the subtractive primaries of the dyer. One of the greatest difficulties, and one of the greatest opportunities, for the Colour Group, will be to bridge the gap between the additive colour mixture familiar to the physicist and the subtractive colour mixture always employed by the dyer. This is unfortunately a by no means simple matter and it has the, to the dyer, added disadvantage of requiring a fair amount of mathematics. Mr. Perry did not spare the chemists and dyers, and later in the meeting urged that each member of the Group should be prepared to make the mental effort required to understand the approach of other members to the problems of colour. At the same time, those taking part in the discussion must bear in mind that many of their audience have been trained along very different lines from their own and they, too, should make an effort to express themselves in the simplest possible manner.

It was inevitable that at the opening meeting a number of points would arise that had little direct bearing on colour tolerance, and it was especially interesting to notice how frequently references to colour-blindness occurred, suggestions being made 
that a test for colour-blindness should be instituted in schools. The effect of eyestrain when using instruments, the sensitivity of the unaided eye in detecting small colour differences compared with the sensitivity when a colorimeter is employed, the mathematical developments of colorimetry in the United States, the merits of spectrophotometers, all came in for some comment. The excellent attendance, the interest of the members and the wealth of material as subjects for discussion, augur well for the future of the Group.

\section{ELECTRICALLY DRIVEN SHIPS}

$\mathrm{I}^{\mathrm{N}}$ war-time, while the question of capital cost is not the most important consideration, anything which increases the tonnage of the Navy and of the merchant fleet deserves serious attention. During the War of 1914-18, the attempts of the German Navy to blockade the British Isles by the unrestricted use of the submarine presented a similar problem. It was solved by the adoption of entirely novel methods. In addition to methods of speeding up ships of conventional design, the so-called 'fabricated" ship was constructed, and bridge builders and constructional engineers were called in to help. The parts of the hull were constructed, usually inland, and were sent to a convenient location on the coast where they were erected and launched.

In the Electrical Review of January 24, Mr. A. Regnauld makes a useful contribution to the solution of the problem by pointing out that ships' output can be increased by increasing their speed. This can be done by utilizing the large available electrical manufacturing industry for the production of the propelling machinery, and leaving the shipyards to deal with the production of the hulls.

In present circumstances, the manufacture of electric generating equipment is largely in abeyance and so also is the production of prime movers. If the shipyards could increase the output of hulls, the propelling equipment for the additional vessels could be constructed in its entirety by the electrical manufacturers and associated boiler manufacturers when steam turbines are installed. In all modern turbodriven steamships, some form of speed-reducing gearing must be employed. The most efficient propeller speed for merchant tonnage, namely, 12-15 knots, is 100-120 r.p.m. The economic speed of the steam turbine is very high, somewhere about 3,000 r.p.m., varying according to size. Neither the turbine nor the heavy-oil engine can be readily reversed. This involves the use of specially constructed turbines running in the reverse direction to the main turbines. These astern turbines are often of sufficient size to develop more than 50 per cent of the ahead power. They may only be required for half an hour or so, at the beginning and end of a voyage when manœuvring out of and into port. This represents a very uneconomical effect.

With the electric drive, particularly if two or more generators are employed to supply the maximum power, a very high degree of flexibility is obtained at all the different speeds used in service. If bridge control be fitted, it would prove of supreme value in any emergency which might arise. The maintenance charges comprised of overhauls and repairs are generally in favour of the electrically driven ship.

\section{FORTHCOMING EVENTS}

[Meeting marked with an asterisk is open to the public.]

\author{
Saturday, March 8
}

Society for Culturar. Relations with the U.S.S.R. (at the Royal Hotel, Woburn Place, London, W.C.1), at 1 p.m.-Prof. George Thomson: "Anthropological Theory in the U.S.S.R."

\section{Monday, March ro}

Royal Geographical Society (at Kensington Gore, London, S.W.7), at 5 p.m.-Mr. Gerald Seligman : "The Structure of a Temperate Glacier".

\section{Tuesday, March II}

Chemical Enginefring Group in conjunction with the Institution of Chemical Engineers (Joint Meeting) (in the Rooms of the Chemical Society, Burlington House, Piccadilly, London, W.1.), at 2.30 p.m.-Mr. E. W. Murray: "Ventilation (Natural and Artificial) in relation to the Blackout".

Illuminating Engineering Society (at the E.L.M.A. Lighting Service Bureau, 2 Savoy Hill, London, W.C.2), at 2.30 p.m.-Addresses on "Recent Work on A.R.P. Lighting Problems."

\section{Wednesday, March 12}

Geological Societry of London (at Burlington House, Piccadilly, London, W.1), at 2.30 p.m.-Annual Meeting. Prof. P. G. H. Boswell, F.R.S.: Presidential Address-Part 1: "The Status of Geology, a Review of Present Conditions"; Part 2: "The Stability of Minerals in Sedimentary Rocks".

\section{Friday, March 14}

Royal Astronomical Society (at Burlington House, Piccadilly, London, W.1.) at 3 p.m. Annual General Meeting. Professor H. C. Plummer, F.R.S.: "The History of the Vertical Telescope."

North-East CoAst Institution of EngINeERS and ShrpbUIlders (in the Mining Institute, Newcastleupon-Tyne), at 6 p.m.-Mr. J. Calderwood : "Some General Observations on Vibration".

\section{APPOINTMENTS VACANT}

APPLICATIONS are invited for the following appointments on or before the dates mentioned:

LECTURER FOR MECHANICAI ENGINEERING SUBJECTs--The Sectetary, Northampton Polytechnic, St. John Street, London, E.G.1 (March 17).

Demonstrator IN BIology--The Principal, Technical College, Kingston-upon-Thames.

Assistant Profkssor of MGTaLluRgy-The Director, Department of Mining and Metallurgical Engineering, Laval University, Quebec City, Canada.

\section{REPORTS AND OTHER PUBLICATIONS \\ (not included in the monthly Books Supplement)}

\section{Great Britain and Ireland}

Finance and the War. An Address given by Prof. F. Soddy to Members of the Parliamentary Labour Party at the House of Commons on Tuesday, November 9, 1940. Pp 16. (London: Economic
Reform Club and Institute.) $3 d$. Report on Conditions in Reception Areas. By a Committee under the Chairmanship of Mr. Geoffrey Shakespeare, M.P. Pp. 18. (London: H.M. Stationery Office.) 3d. net. [291 Tin Research Institute. Publication No. 102: Hot-Tinning; an Account of the Tinning of Steel, Iron, Copper, Brass and Bronze by the Hot-dipping Process. By Dr. C. E. Homer. Pp. 28. (Greenford : Tin Research Institute.)

\section{Other Countries}

Publications of the Alleghany Observatory of the University of Pittsburgh. Vol. 8, No. 5: Observations of Eros, 1930-1931. By Pittsburgh. Vol. 8, No. 5: (Pittsburgh, Pa. : University of PittsN. E. Wagman. Pp. 63-76. (Pittsburgh, Pa.: University of Pitts-
burgh Press.)

Government of Bengal : Department of Agriculture and Fisheries. Report on a Survey of the Fisheries of Bengal. Pp. iif +88 . (Alipore Bengal Government Press.) 